\title{
PARCERIA ENTRE CIÊNCIA DA INFORMAÇÃO E RESPONSABILIDADE SOCIAL UNIVERSITÁRIA PARA FINS DE INCLUSÃO SOCIAL
}

\author{
THE PARTNERSHIP BETWEEN INFORMATION SCIENCE AND UNIVERSITY SOCIAL \\ RESPONSIBILITY AIMING AT SOCIAL INCLUSION
}

\author{
André Anderson Cavalcante Felipe $e^{1}$ \\ Jesiel Ferreira Gomes ${ }^{2}$
}

\begin{abstract}
Resumo: O artigo apresenta o conceito, surgimento e aplicabilidade da responsabilidade social universitária (RSU), trazendo exemplos de sua utilização vinculada à extensão universitária, que demonstra ser uma parceria essencial para oportunizar a inclusão social. Como objetivo discute a atuação da Ciência da Informação (CI) juntamente com a RSU e analisa um projeto de extensão que relaciona o envolvimento de entre ambas as áreas, intitulado "Biblioterapia, informação e terceira idade: a função terapêutica da leitura em idosos asilados na cidade de Cuité - PB como ferramenta de inclusão social da Universidade Federal de Campina Grande (UFCG)". Os resultados mostram que a parceria entre CI e RSU promove impactos positivos junto ao público asilado na cidade de Cuité, visto que, a ação de extensão analisada comprova que a leitura é um importante instrumento de afeto e de sensibilização porque atinge todos os participantes e contribui para a inserção destes no meio social de Campina Grande.
\end{abstract}

Palavras-chave: Ciência da informação. Responsabilidade social universitária. Inclusão social. Extensão universitária. Biblioterapia.

\begin{abstract}
The paper presents the concept, appearing and applicability of university social responsibility (USR), bringing examples of its use linked to university extension, which proves to be an essential partnership to nurture the social inclusion. As goal discusses the performance of Information Science (IS) together with the URS, and analyzes an extension project related to the involvement of both sites, entitled "Bibliotherapy, information and seniors: the therapeutic role of reading in institutionalized elderly in the city of Cuite - PB as a tool for social inclusion, of the Federal University of Campina Grande (FUCG)". The results demonstrate that the partnership between IC and USR promotes positive impacts in the institutionalized public of Cuite city, as, the extension action analyzed proved that reading is an important tool of affection and sensitization, because it reaches all the participants and contributes to their insertion in the social environment of Campina Grande.
\end{abstract}

Keywords: Information science. University social responsibility. Social inclusion. University extension. Bibliotherapy.

\footnotetext{
${ }^{1}$ Doutorando em Estudos da linguagem plea UFRN. Mestre em Ciência da informação Pela UFPB. Graduado em Biblioteconomia pela UFC.Brasil. Email: andreandersonf@gmail.com

${ }^{2}$ Mestre em Ciência da informação Pela UFPB. Graduado em Biblioteconomia pela UFPB. Brasil. Email: jesielgomes@ufcg.edu.br

Recebido em: 05/05/2013 - Aceito em: 28/09/2013.
} 


\section{INTRODUÇÃO}

Na atualidade, a Responsabilidade Social Universitária (RSU) apresenta-se como um elo entre dois mundos diferentes, onde o primeiro é a universidade e os elementos que a compõem: docentes, estudantes, currículo, pesquisa, extensão etc.; e o segundo é a sociedade, com suas situações de iniquidade, pobreza, antagonismo e outras características advindas da globalização, como a efemeridade, os avanços tecnológicos, dentre outros (WAGENBERG, 2006). Podemos inferir que existe uma relação de divergência e dependência entre universidade e sociedade, de modo que, cabe a RSU, atuar de forma a promover ordem e equilíbrio nessa relação.

Para La Jara, Fontecilla e Troncoso (2006), a RSU é a capacidade que a universidade tem de difundir e colocar em prática um conjunto de princípios e valores gerais e específicos, por meio de quatro processos considerados essenciais: gestão, docência, pesquisa e extensão universitária. Essa última caracteriza-se como o foco do nosso trabalho, mesmo sendo considerada a menos reconhecida da universidade como destaca Calderón (2006), ao apresentar fatores que corroboram para esta assertiva, como por exemplo, a compreensão equivocada do conceito de extensão universitária; a falta de recursos e a inexistência, na maioria das vezes, de políticas institucionais extensionistas sérias e consistentes.

As discussões em torno da RSU têm gerado certa resistência na comunidade acadêmica, devido à existência de um viés ideológico muito presente na intelectualidade brasileira, visto que, para alguns professores, a RSU

\footnotetext{
[...] trata-se de um conceito procedente de uma matriz empresarial que não se adequaria à natureza pública das IES, uma vez que a universidade não seria uma empresa. Para outros, trata-se de um conceito que se enquadra na lógica neoliberal e que responde aos interesses de um projeto de sociedade excludente, impulsionado pelas grandes agências multilaterais (Banco Mundial, FMI, entre outros), com os quais a universidade não poderia compactuar. (CALDERÓN, 2006, p. 07).
}

Contudo, segundo Vallaeys (2006), a universidade deve superar o enfoque da projeção social e extensão universitária como apêndices bem intencionados de sua função central de formação estudantil e produção de conhecimentos, a fim de atender ao que de fato exige a RSU. Na mesma linha de pensamento, Severino (2008) afirma que a implementação dos processos de ensino e de aprendizagem na universidade 
precisa ser intencionalmente assumida e efetivamente praticada, sob pena de se comprometer o processo, fazendo-o perder sua consistência e eficácia, ou seja, o conhecimento deve ser construído pela experiência do estudante, ao invés de ser adquirido de forma passiva e sem reflexão.

A instituição acadêmica precisa refletir sobre si mesma, no contexto de seu entorno social, de modo a fazer uma análise de sua responsabilidade e, sobretudo, de sua parcela de culpa nos problemas crônicos da sociedade. (VALLAEYS, 2006, p. 38).

Em uma visão oposta à visão da extensão universitária, como sendo menos importante, reconhecida e valorizada do que a pesquisa e o ensino na universidade entendemos que de fato, a extensão é uma das principais formas ou a forma inicial de aproximação entre as instituições de ensino superior (IES) e setores desfavorecidos da sociedade.

\begin{abstract}
A extensão se torna exigência intrínseca do ensino superior em decorrência dos compromissos do conhecimento e da educação com a sociedade, uma vez que tais processos só se legitimam, inclusive adquirindo sua chancela ética, se expressarem envolvimento com os interesses objetivos da população como um todo. [...] Com efeito, é graças à extensão que o fazer pedagógico ganha sua dimensão política, porque a formação do universitário pressupõe também uma inserção no social, despertando-o para o entendimento do papel de todo saber na instauração do social. [...] Deste modo, a extensão tem grande alcance pedagógico, levando o jovem estudante a vivenciar sua realidade social. É por meio dela que o sujeito/aprendiz irá formando sua nova consciência social. A extensão cria então um espaço de formação pedagógica, numa dimensão própria e insubstituível. (SEVERINO, 2008, p. 27-28).
\end{abstract}

Ao tratarmos da RSU no contexto brasileiro, seguimos a linha de pensamento de Calderón (2006, p.20), por afirmar que as discussões em torno dos rumos da universidade possuem uma conotação político-ideológica que permeia toda sua trajetória histórica, e por propor que a defesa e a disseminação da RSU "parte de uma tradição universitária latino-americana, pautada pela defesa de ideais humanísticos, em prol de uma universidade comprometida na luta contra a pobreza" e a favor da construção de uma sociedade mais justa e democrática. Para evidenciar a importância da RSU, Calderón (2006, p. 9) analisou uma rede universidades chilenas que se

[...] reuniram em torno do conceito de RSU com intuito de aprimorar a gestão universitária e de criar uma cultura coletiva a partir da implantação de um projeto em comum, denominado Universidad Construye País, que busca expandir o conceito e a prática da RSU no sistema universitário 
chileno. Iniciado em 13 universidades públicas, o projeto começa a se expandir e pretende também atingir aproximadamente 30 universidades privadas existentes no Chile. [...] A experiência chilena constitui-se caso paradigmático. Dirigentes universitários e suas respectivas comunidades acadêmicas se debruçaram sobre a temática da RSU, desenvolvendo uma interessante proposta de promoção da responsabilidade social universitária, a mesma que pode servir para repensar os sistemas universitários dos diversos países irmãos da América Latina e do Caribe. Trata-se de uma proposta que envolve conceitualização, princípios, valores e ferramentas de gestão universitária, com o intuito de observar, avaliar e realizar ações corretivas quando necessário.

Duas contribuições são mencionadas por Calderón (2006, p. 15) ao analisar a conceitualização feita pelos representantes das 13 universidades chilenas participantes do Projeto Universidad Construye País: "a importância dada à gestão da universidade, pela definição de mecanismos gerenciais que viabilizam o ensino, a pesquisa e a extensão; e os princípios e valores que devem nortear toda a engenharia institucional postos no centro da estrutura da universidade". Dessa forma, a RSU exige que setores da instituição se articulem em projetos de promoção social "de princípios éticos e de desenvolvimento social eqüitativo e sustentável, com vistas à produção e transmissão de saberes responsáveis e à formação de profissionais cidadãos igualmente responsáveis”. (VALLAEYS, 2006, p. 39).

Ao efetivar a implementação da RSU nas IES do Brasil, veremos de forma promissora o aumento do princípio da responsabilidade e do seu exercício entre os sujeitos que constituem as universidades brasileiras. Em outras palavras, a RSU contribui para a promoção de uma prática pedagógica condizente, onde o que conta não é mais a capacidade de decorar e memorizar milhares de dados, fatos e noções, mas a capacidade de entender, refletir e analisar os dados, os fatos e as noções. (SEVERINO, 2008).

Cientes da importância de evidenciarmos ações que promovem melhorias educacionais e sociais através da utilização da extensão universitária, este artigo tem como objetivo apresentar a atuação da Ciência da Informação em parceria com a RSU, apresentando as ações do projeto "Biblioterapia, informação e terceira idade: a função terapêutica da leitura em idosos asilados na cidade de Cuité - PB como ferramenta de inclusão social da Universidade Federal de Campina Grande (UFCG)", que analisa as práticas informacionais dos idosos que vivem em ambiente de asilo a 
fim de estabelecer o acesso à informação e a cidadania através da leitura mediada pela biblioterapia.

\title{
2 CIÊNCIA DA INFORMAÇÃO E A RESPONSABILIDADE SOCIAL UNIVERSITÁRIA
}

A Ciência da Informação (CI) surge no horizonte de transformações das sociedades contemporâneas que passaram a considerar o conhecimento, a comunicação, os sistemas de significado e os usos da linguagem como objetos de pesquisa científica e domínios de intervenção tecnológica. (GONZÁLEZ DE GOMEZ, 1993). Ela constituía-se ao mesmo tempo, como uma nova demanda de cientificidade e como um sintoma das mudanças em curso que afetariam a produção e direção do conhecimento no ocidente.

A CI é caracterizada como uma ciência pós-moderna que tem objeto de estudo relacionado a múltiplos domínios da ciência e tecnologia denominado informação. Possui uma natureza interdisciplinar que se estabelece de forma diferenciada entre as áreas do conhecimento, levando em conta as mudanças sociais ocasionadas pela informação.

\begin{abstract}
A ciência da informação não se desenvolveu a partir de outro campo de estudo (como a psicologia), nem da intersecção de dois campos (como a bioquímica), mas a partir das exigências de uma área de trabalho prático, denominada "documentação" ou "recuperação da informação". Embora a introdução de novas tecnologias, particularmente do processamento eletrônico de dados, tenha determinado a emergência desta disciplina, as contribuições para o nascimento da "ciência da informação" vieram de muitas disciplinas distintas (devido às diversas formações das pessoas que ingressaram num campo em que não havia nenhum sistema educacional estabelecido) e foram provocadas por uma série de diferentes interesses (devido às diferentes áreas de aplicação envolvidas com o trabalho de informação). (NEVELING; WERSIG, 1975, p.1).
\end{abstract}

Percebemos que a CI não segue um estilo unidimensional e estabelece uma relação direta ou indireta com outras formas de conhecimento, usufruindo e sendo usufruída por elas. Outro fato relevante é a importância que dá ao conhecimento do senso comum, enquanto saberes necessários para uma melhor relação entre ciência e sociedade. 
Dessa forma a ciência pós-moderna ao sensocomunizar-se não despreza o conhecimento que produz tecnologia, mas entende que, tal como o conhecimento se deve traduzir um autoconhecimento, o desenvolvimento tecnológico deve traduzir-se em sabedoria de vida. (BOAVENTURA SANTOS, 1988, p. 70).

O aspecto pós-moderno está fundamentado no conceito de que a CI representa uma matéria (especialidade), que não pode ser classificada entre outras matérias. Pelo contrário, a Ciência da Informação perpassa outras disciplinas. Ela contém partes dessas disciplinas, que as influencia por meio dos objetos de estudo de cada uma delas. (WERSIG, 1993).

As origens da área de Ciência da Informação remetem a uma série de estudos independentes, que partindo de objetivos e pontos de vista distintos vêm consolidando este campo científico. Deste modo, como era de se esperar, as várias vertentes que influenciaram o desenvolvimento da Ciência da Informação, acabaram por delimitar paradigmas epistemológicos distintos, embora inter-relacionados e complementares.

Conforme afirma Capurro (2003), torna-se fundamental a realização de estudos epistemológicos sobre os campos de atuação da área de Ciência da Informação que apresentem as similaridades e diferenças existentes entre o conceito de informação nessa ciência em relação a outros campos científicos.

Verificamos a existência de três correntes paradigmáticas: o paradigma físico, o paradigma cognitivo e o paradigma social, entendidas com perspectivas teóricas distintas, mas, inter-relacionadas e complementares em determinadas situações.

Para González de Goméz (2000) presenciamos na sociedade a reformulação das infraestruturas de informação que se manifestam nos avanços nas tecnologias dos supercomputadores, na robótica na produção industrial, na expansão da microeletrônica potencializada pelas redes de comunicação remota, abrangendo toda a extensão do tecido social, contribuindo para uma maior perspectiva de atuação da CI no paradigma social que tem como consequência prática,

Abandonar a busca de uma linguagem ideal para representar o conhecimento ou de um algoritmo ideal para modelar a recuperação da informação, como aspiram ao paradigma físico e o cognitivo, pois considera as possíveis perspectivas ou pontos de acessos distintos de acordo com o interesse do usuário ou comunidade. (CAPURRO, 2003, p. 9). 
Em outras palavras, a informação é entendida como fenômeno social coletivo, estruturas de conhecimento e instituições de memória das comunidades. Para Nascimento e Marteleto (2004), o objeto de trabalho das comunidades encontra-se refletidos nos padrões de cooperação, nas formas de linguagem e comunicação, nas estruturas e organizações do conhecimento, nos sistemas de informação, na literatura (e suas formas de distribuição) e nos critérios de relevância.

No atual contexto da sociedade um dos objetivos da CI seria contribuir para a informação se tornar um elemento de inclusão social, trazendo desenvolvimento para os indivíduos e seus grupos sociais. Se considerarmos o conhecimento como resultado da interação do sujeito com o meio social, tecnológico, político e cultural, seremos de acordo que tal situação apresenta-se como desafio metodológico para a Ciência da Informação, o deslocamento do individualismo metodológico para o seu oposto, o coletivismo metodológico.

Frente a essa postura, constatamos que a CI nos últimos tempos tem demasiada preocupação com os modos com que a informação provê aos indivíduos possibilidades de melhoria social e consequentemente a cidadania, entendida aqui "como um status concedido àqueles que são elementos integrais de uma comunidade". (TARGINO, 1991, p. 12).

Nesse sentido, cidadania implica um conceito de igualdade, uma vez que todos os que possuem esse status são iguais, no que diz respeito aos direitos e obrigações pertinentes ao status (TARGINO, 1991). Mas, contrariamente à ideia de igualdade que a cidadania sugere a estratificação social, que concede o status, é um sistema de desigualdade que se acentua e se agrava no sistema capitalista.

A autora referiu-se ao caso específico da educação como elemento basilar dos direitos sociais, afirma que o direito à educação afeta o status da cidadania, se entendermos o direito à educação como o direito do cidadão adulto ter sido educado e informado.

As universidades brasileiras assumem um papel fundamental nesse processo, já que viabilizam o projeto da sociedade e do conhecimento e operacionaliza a formação e o exercício da cidadania.

Entretanto, ao nos reportamos para as Universidades Federais Brasileiras, perceberemos que as ações voltadas à promoção de RSU permanecem em parte, em 
nível de discurso como mostra Wagenberg (2006, p. 27) ao afirmar que "o atual modelo universitário encontra-se em decadência. Cada vez mais é questionado o papel da universidade como cultivadora de identidade e cultura da Nação-Estado". A promoção de uma RSU ampla possibilitaria novas formas de combate a essa situação, de forma a está comprometida a,

facilitar o desenvolvimento individual de seus alunos. Entretanto, é necessário reconhecer que o desenvolvimento não é simplesmente algo acadêmico e informativo. Desenvolvimento consiste em ensinar ao estudante a pensar por si mesmo; ajudá-lo a fortalecer seus próprios ideais, opiniões e ideias e ensinar-lhe a realidade do mundo. Realidade que nos mostra um mundo onde existem mais de um bilhão de pessoas vivendo em situação de pobreza 10, 815 milhões das quais desnutridas, entre outros horrores inconcebíveis. Ao ensinar esta realidade, a universidade passa a assumir seu compromisso social e o estudante começa a compreender sua própria responsabilidade. É aqui que a transformação se inicia - quando se constrói a universidade ao redor de um núcleo social e não como um processo paralelo como o da projeção social. (WAGENBERG, 2006, p.30).

Frente às disparidades da sociedade no que competem ao avanço tecnológico, as disputas entre países por informação e conhecimento, a corrida da ciência e armamentista, o consumismo e individualismo, enfim, todos os novos paradigmas que surgem motivados pelos interesses do capitalismo globalizado, o sistema educacional aparece-nos como um fator de extrema importância para o desenvolvimento de países emergentes como o Brasil.

A sociedade vigente está a exigir indivíduos com a capacidade de utilizar a informação de modo rápido e flexível, o que coloca problemas ao nível de acesso, uso e organização da informação. Por outro lado, os indivíduos precisam

saber qual informação procurar e onde procurar [distinguindo] o que é relevante e irrelevante, [porquanto] em razão da multiplicidade de utilizações que potencialmente encerra, [a informação] precisa ser organizada por quem a procura, a quem compete agora por em ação a sua mente interpretativa, seletiva, sistematizadora e criadora (ALARCÃO, 2003, p. 25).

Isso implica a inclusão de estratégias no processo ensino e aprendizagem, tais como "criar, estruturar e dinamizar situações de aprendizagem e estimular a aprendizagem e a autoconfiança nas capacidades individuais para aprender". (ALARCÃO, 2003, p. 30). 
Somos de acordo que a prioridade em uma ação baseada na RSU deve desenvolver mecanismos que promovam a inclusão de indivíduos que ainda não exercem cidadania por não deter condições de usufruir das informações produzidas na sociedade. Nesse contexto, a parceria entre Ciência da informação e as ações de responsabilidade surtiram grandes efeitos como observaremos a seguir.

\section{O PROJETO BIBLIOTERAPIA, INFORMAÇÃO E TERCEIRA IDADE: A FUNÇÃO TERAPÊUTICA DA LEITURA EM IDOSOS ASILADOS NA CIDADE DE CUITÉ - PB COMO FERRAMENTA DE INCLUSÃO SOCIAL DA UFCG - CES}

Imaginar a CI, a RSU e demais terminologias que representam o universo acadêmico nos remete inicialmente a contextos nos quais percebemos pessoas qualificadas, livros, tecnologia, entre outros elementos que fazem parte deste universo de saber, de cultura e de conhecimento. Todavia, ao submergir deste plano, percebemos que há diversos atores sociais, em microcontextos, alheios a essa dinâmica de busca, de produção e de consumo de informação, como também, desprovidos da utilização de toda a parafernália associada a este bojo. Esses atores são representados pelos idosos, mais especificamente, os idosos asilados.

Além do isolamento social e cultural, estes idosos asilados foram alijados do convívio familiar e do relacionamento de trabalho. Eles não são consultados para as decisões políticas, sociais e culturais, sendo considerados apenas "entulhos", de "coisas" que se quer esconder. Esses sujeitos não podem ser comparados com os idosos detentores de poder econômico, pois, esses asilados são pessoas das quais a sociedade não quer lembrar, muito embora ela saiba que lá, mesmo adormecido, esse “incômodo" exista.

Ressaltamos que o envelhecimento da população é um dos maiores triunfos da humanidade e é ao mesmo também um dos seus maiores desafios. Ao entrar no século XXI, o envelhecimento global causou um aumento das demandas sociais e econômicas em todo o mundo, e em relação ao Brasil, podemos afirmar que a população brasileira está envelhecendo assustadoramente e a sociedade ainda continua indiferente a essa questão, talvez, pelo fato do Brasil ter sido considerado o país dos jovens, onde a juventude formava a maioria da população. 
O que devemos fazer e o que esperar de uma sociedade jovem que começa a envelhecer rapidamente? Que valores desaparecem e que outros surgem nesse constante processo de transformação? Estamos aceitando a velhice como um fenômeno social e estamos preparados para conviver com ela? Com essas inquietações, acreditamos que a biblioterapia constitui uma forma expressiva desses fenômenos porque pode atribuir sentido à vida do idoso, no que diz respeito à questão da cidadania e terceira idade, analisando-a sem dissociá-la da situação econômica, social e política vigente, na expectativa dos idosos conseguirem exercer cidadania de forma plena.

Nessa perspectiva, entendemos que a RSU traduzida no projeto "Biblioterapia, informação e terceira idade", desenvolvido pela Biblioteca do Centro de Educação e Saúde (CES) com discentes dos cursos de licenciatura e/ou graduação ofertados pela UFCG, articula leitura com lazer e cultura e desenvolve o potencial criativo dos idosos, estimula a sensação de serem úteis à sociedade, tornando-os mais conscientes de sua cidadania, visto que "cada tempo da vida tem seu propósito e sua beleza". (MAGALHÃES, 1987 p. 23).

Assim, Simões (1998, p. 29) "entende que a velhice não significa uma decadência e sim uma sequência da vida". Na mesma linha de pensamentos apontamos Salgado (1997, p. 18 apud GOMES; CASTRO, 2007, p. 30) que propõe uma reflexão sobre a posição moral da categoria velho, afirmando que

\begin{abstract}
as sociedades precisam, urgentemente, reformular suas idéias sobre a velhice eliminando as posturas preconceituosas que tanto aviltam a dignidade que durante milênios de evolução, a espécie humana tem lutado para conquistar. É necessário que se prolonguem ou se criem oportunidades novas para os que envelhecem, mantendo-os ativos e participantes segundo suas condições psicofísicas para, com isso, devolverlhes sua total dimensão.
\end{abstract}

Conforme a Organização Mundial da Saúde (2002 apud GOMES; CASTRO, 2007), os países podem custear o envelhecimento se os governos, as organizações internacionais e a sociedade civil, providenciarem políticas e programas de "envelhecimento ativo" que melhorem a saúde, a participação e a segurança dos cidadãos e cidadãs mais velhos.

Dentre estas políticas, o uso da leitura com objetivo terapêutico é uma ferramenta que surte efeitos, tanto que é antigo o seu uso, e muitos registros atestam 
essa utilização. No antigo Egito, o Faraó Ramsés II mandou colocar no frontispício de sua biblioteca a frase "Remédios para a alma". (ALVES, 1982). As bibliotecas egípcias se localizavam em templos denominados de "casas de vida", locais de conhecimento e espiritualidade. Entre os romanos, Aulus Cornelius Celsus também associou a leitura com tratamento médico, ao recomendar a leitura e discussão das obras de grandes oradores como recurso terapêutico no desenvolvimento da capacidade crítica dos pacientes (ORSINI, 1982). "Tesouro dos remédios da alma" era a inscrição que havia na biblioteca da Abadia de São Gall, durante a Idade Média (ALVES, 1982).

A biblioterapia foi definida pela primeira vez em 1941 no Dorland's Illustrated Medical Dictionary, como o emprego de livros através de literatura dirigida aplicada ao tratamento de doentes mentais (RATTON, 1975). Em 1961, o Webster's Third Internacional Dictionary define a biblioterapia como sendo o "uso de material de leitura selecionada, como adjuvante terapêutico em Medicina e Psicologia", além de atuar como "guia na solução de problemas pessoais através de leitura dirigida", sendo esta última definição, adotada como oficial pela Associação para Bibliotecas de Hospitais e Instituições. (RATTON, 1975, p. 15).

A biblioterapia é uma técnica que pode ser utilizada para fins de diagnóstico, tratamento e prevenção de moléstias e problemas pessoais, como também, auxilia no autoconhecimento pela reflexão, reforça padrões sociais desejáveis, proporciona desenvolvimento emocional pelas experiências lúdicas e auxilia na mudança e comportamento. (ORSINI, 1982 apud CALDIN, 2001),

Como se pode ver, a Biblioterapia é utilizada para complementar a educação formal, através de discussões orientadas e leitura dirigida. Ela é aplicada como uma terapia por alguém especificamente treinado e em caráter preventivo. Sua aplicação é realizada preferencialmente em grupos homogêneos com os mesmos interesses e principalmente, na mesma faixa etária.

Aproveitando todo este arcabouço, o projeto "Biblioterapia, informação e terceira idade", vem sendo desenvolvido há três anos junto ao Asilo e casa do idoso Vó Filomena Maria da Conceição (ASILAR), na cidade de Cuité-PB, localizado no Curimataú Paraibano a 264 km da capital paraibana. 




FIGURA 1 - Asilo e casa do idoso Vó Filomena Maria da Conceição (ASILAR)

Fonte: (GOMES; CASTRO, 2007).

Os idosos asilados na cidade de Cuité-PB vivem em um único espaço existente em toda a região, no qual, encontram-se, hoje, 27 idosos os quais são vítimas de conflitos emocionais provenientes da ausência de relacionamento familiar e outros fatores. O lado emotivo e afetivo desses idosos são pontos fundamentais a serem trabalhados. Eles vieram para o ASILAR por motivos dos mais variados, desde o abandono familiar, a violência doméstica, os problemas de saúde e principalmente, a total falta de condições econômicas de subsistência.

Em parte, o ASILAR é mantido pelos próprios idosos que tem a aposentadoria proveniente de labuta rural, e por outro lado, a prefeitura do município tem como contra partida, a cessão de funcionários para cuidar destes idosos, muito embora, não seja um trabalho especializado, é sobremaneira, uma atenção digna que se presta a esta população.

Como a cidade de Cuité é desprovida de infraestrutura e atenção, por parte das autoridades públicas na implantação de políticas voltadas para esta parcela 
populacional, cabe aos órgãos circunvizinhos a responsabilidade de prestar toda e qualquer forma de ajuda a estes sujeitos sociais.

Atualmente, após a contribuição que a universidade presta a este público, percebemos o quanto novos parceiros já adentraram no ambiente até então isolado dos idosos do ASILAR, dentre os quais podemos destacar: o projeto Mandalla, o grupo de jovens de terapia de grupo, os grupos de orações de Cuité, entre outros que vislumbraram nestes idosos a possibilidade de contribuir para a qualidade de vida e inserção destes na sociedade que até então os ignorou.

Durante toda a realização do projeto são abordados temas dos quais foram tidos como metas para a realização da biblioterapia. Os idosos são assistidos de forma integrada, onde ocorre uma interação contributiva para satisfação dos mesmos. Levamos até eles a importância da leitura. Os textos lidos abordam temas relacionados à velhice, aos direitos dos idosos, além de textos bíblicos. Após a realização das leituras, é perceptível o quanto eles despertam seu senso crítico, dando suas opiniões e expondo sua capacidade de discutir sobre determinados assuntos abordados, surpreendendo até mesmo os seus cuidadores, que até então lidavam com pessoas quietas, introspectivas e passivas.

Em conversas abertas, os idosos expõem suas vidas ao relatar acontecimentos e emoções marcantes, sendo este o momento mais interesse do processo biblioterápico, no qual, por meio da vivência destes, podemos adentrar em suas vidas ao tempo que permitimos com a escuta e fazer com que eles possam sentir-se parte do convívio em que estão inseridos.

A dificuldade encontrada durante a realização do projeto foi a de trabalhar a leitura propriamente dita, uma vez que, alguns idosos são portadores de deficiências físicas e/ou psíquicas, como a visual, auditiva, mental e física. Tal situação impossibilita a compreensão de forma plena do que se ler, mas, não impede a participação e troca de saber entre os representantes do projeto e os participantes do processo.

A leitura de afeto e de sensibilização desenvolvida junto ao público asilado na cidade de Cuité tem impacto positivo, uma vez que, ela se caracteriza como uma linguagem universal e atinge a todos sem distinção. Isso é a maior prova da efetiva funcionalidade e abrangência do projeto e da permissão da inserção desses sujeitos 
por meio de um projeto de extensão, de modo que a RSU praticada pelo CES da UFCG, através de sua biblioteca, é certamente um pilar de constituição exemplar para outros projetos.

\section{PALAVRAS FINAIS}

Nas IES, precisamos estar no front da luta pelo conhecimento da realidade para que a formação acadêmica seja perpassada por atitudes de responsabilidade. Fazse necessário, que cada disciplina de cada curso, discuta sobre comprometimento ético de professores, alunos e sociedade, contribuindo para que todos exercitem a ética de si para si, e aprimorem a auto-análise, a autocrítica, a tolerância, a tomada de responsabilidade; que na formação dos estudantes, persigam-se os resultados positivos e, por via de consequência, comunidades socialmente responsáveis que pensem por si e fortaleçam seus ideais e opiniões em favor das populações marginalizadas e excluídas; que promovam mudanças econômicas e sociais isoladamente ou em parceria com outras instituições e/ou governos. Enfim, que os cidadãos formados não discriminem, não permitam ser discriminados e também não se discriminem.

As atitudes de responsabilidade ética e social que começam a ser praticadas no meio universitário, ainda necessitam de muito fermento para se reproduzirem de forma amplificada. Do contrário, a emissão de leis, citando as situações de discriminação e as penas para quem as descumpre, torna-se dispensável. No entanto, a responsabilidade pela inclusão não é somente das IES, nem a discriminação se resolve via legislação, mas pode ser iniciada nas discussões e nas propostas de grupos de estudos, em salas de aulas, em trabalhos de extensão, em pesquisas de Mestrado e Doutorado. Referimo-nos a estudantes e pesquisadores ao redor de um núcleo, discutindo temas dessa magnitude, transversalmente em cursos, programas e disciplinas, objetivando formar cidadãos ética, e socialmente, responsáveis. Por sua vez, partícipes de uma sociedade sem que seja preciso cotas para judeus, negros, índios, nordestinos, mulheres, homossexuais e outras minorias, porque incorporariam todas e todos. Enfim, sem a necessidade de legislações que prevejam castigos para os discriminadores, vez que estes inexistirão, o que dispensará, por via de consequência, a cobrança de atitudes ou comportamentos éticos esperados (no sentido positivo). 
Retornando, repetindo e reforçando! Imaginamos a RSU com atitudes de respeito, praticadas com comportamentos éticos, moralmente corretos; com respeito aos padrões universais de direitos humanos e de cidadania e com a participação de toda a sociedade; com respeito às diversidades e aos diferentes, sem discriminações. 


\section{REFERÊNCIAS}

\section{ALARCÃO, Isabel. Professores Reflexivos em uma Escola Reflexiva. 2. ed. São} Paulo: Cortez, 2003.

ALVES, Maria Helena Hess. A aplicação da biblioterapia no processo de reintegração social. Revista Brasileira de Biblioteconomia e Documentação, v. 15, n.1/2, p. 5461, jan./jun. 1982.

CAPURRO, R. Epistemologia e ciência da informação. In: ENCONTRO NACIONAL DE PESQUISA EM CIÊNCIA DA INFORMAÇÃO - ENANCIB, 5., 2003. Belo Horizonte. Anais... Belo Horizonte: UFMG, 2003.

CALDERÓN, Adolfo Ignácio. Responsabilidade social universitária: contribuições para o fortalecimento do debate no Brasil. Estudos: Revista da Associação de Mantenedores de Ensino Superior, Brasília, v. 24, n. 36, p. 07 - 22, jun. 2006.

CALDIN, Clarice Fortkamp. A leitura como função terapêutica: biblioterapia. Encontros Bibli: revista eletrônica de biblioteconomia e ciência da informação, Florianópolis, n. 12, dez. 2001. Disponível em:

<http://www.ced.ufsc.br/bibliote/encontro/bibli12/caldin.html>. Acesso em: 09 out. 2013.

GOMES, Jesiel Ferreira; CASTRO, Rachel Barbosa de. Campo de trabalho do profissional da informação: biblioterapia para idosos. In: CONGRESSO BRASILEIRO DE BIBLIOTECONOMIA, DOCUMENTAÇÃO E CIÊNCIA DA INFORMAÇÃO - CBBD, 22., 2007. Brasília. Anais... Brasília: CBBD, 2007.

GONZÁLEZ DE GOMEZ, Maria Nélida. A representação do conhecimento e o conhecimento da representação: algumas questões epistemológicas. Ciência da Informação, Brasília, v. 22, n. 3, p. 217-222, set./dez. 1993.

LA JARA, Mónica Jiménez de; FONTECILLA, José Manuel de F.; TRONCOSO, Catalina Delpiano. Responsabilidade social universitária: uma experiência inovadora na América Latina. Estudos: Revista da Associação de Mantenedores de Ensino Superior, Brasília, ano 24, n. 36, p. 57 - 74, jun. 2006.

MAGALHÃES, Dirceu Nogueira. A invenção social da velhice. Rio de Janeiro: Copacabana, 1987.

NEVELING, U.; WERSIG, G. Os fenômenos de interesse para a ciência da informação. 1975. Disponível em:

<http://www.alvarestech.com/lillian/GestaoDaInformacao/Rogerio/WersigNeveling.p df >. Acesso em: 04 maio 2013.

ORSINI, Maria Stella. O uso da literatura para fins terapêuticos: biblioterapia.

Comunicações e Artes, São Paulo, n. 11, p. 139-149, 1982. 
RATTON, Ângela Maria Lima. Biblioterapia. Revista Escola de Biblioteconomia da UFMG, Belo Horizonte, v. 4, n. 2, p. 198 - 24, set. 1975.

SALGADO, Sebastião. Livro terra. São Paulo: Schwarcz, 1997.

SANTOS, Boaventura de Sousa. Um discurso sobre as ciências na transição para uma ciência pós-moderna. Estudos Avançados, São Paulo, v. 2, n. 2, p. 46-71, 1988.

SIMÕES, Regina. Corporeidade e terceira idade: a marginalização do corpo idoso. 3. ed. Piracicaba: Unimep, 1998.

TARGINO, M. das G. Biblioteconomia, informação e cidadania. Revista Escola de Biblioteconomia da UFMG, Belo Horizonte, v. 20, n. 2, p. 149 a 160, jul./dez. 1991.

VALLAEYS, François. Que significa responsabilidade social universitária? Estudos: Revista da Associação de Mantenedores de Ensino Superior, Brasília, v. 24, n. 36, p. 35-56, jun. 2006.

WAGENBERG, Alan. A urgência da responsabilidade social universitária. Estudos: Revista da Associação Brasileira de Mantenedoras de Ensino Superior. Brasília, v. 24, n.36, p. 27-34, jun. 2006.

WERSIG, G. Information Science: The study of postmodern knowledge usage.

Information Processing and Management, v. 29, n. 2, p.229-239, 1993.

\section{Como citar este artigo:}

FELIPE, André Anderson Cavalcante; GOMES, Jesiel Ferreira. Parceria entre ciência da informação e responsabilidade social universitária para fins de inclusão social. Rev. digit. bibliotecon. cienc. inf., Campinas, SP, v.12, n.3, p.147-163, jan/abr. 2013. ISSN 1678765X. Disponível em: <http://www.sbu.unicamp.br/seer/ojs/index.php/rbci>. Acesso em: 30 jan. 2014. 